MILITARY TECHNICAL COLLEGE CAIRO - EGYPT

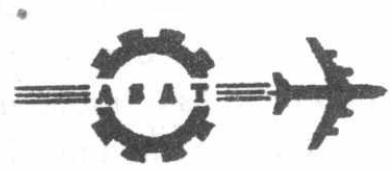

$7^{\text {th }}$ INTERNATIONAL CONF. ON AEROSPACE SCIENCES \& AVIATION TECHNOLOGY

\title{
THE TECHNOLOGICAL PRODUCTION OF PORTABLE NUCLEAR RADIATION METERS
}

\author{
M.M. EL-DESSOUKY*
}

\begin{abstract}
The study explains the design considerations of Gieger-Muller Tube (GMT). The results obtained from the designed GMT in the laboratory under different conditions is given together with a discussion of the results. The puplication shows also the block diagram of some proposed and designed nuclear radiation meters. It demonstrates also some measured data on the designed instruments that ensure the suitability and accuracy of these designed instruments for use in the nuclear radiation laboratories.
\end{abstract}

\section{KEYWORDS}

Radiatiom / Meters / Technological production / Portable meters / Nuclear Measurement.

\section{INTRODUCTION}

The proable nuclear radiation meters consist mainly from sensors and convertor. The sensors detect the nuclear radiation via producing electric pulses whose characteristics depend on the radiation paramaters. The convertors transfere the small DC voltage of small battery to high stabilized one for the operation of detectors that require high stabilized voltage. The majority of radiation meters utilize the GMT as a detector due to its high sensitivity.

GMT is very sensitive for ionizing radiation but it can not be used for measuring energy spectrum. It can measure also UV radiation $[1,2]$. It consists of thin electrode which is connected with the high positive potential and cathode in a glass tube. The dimensions of the electrodeand the tube as well as the pressure and type of filling gas depend on the trange of measurement in which the GMT will be used, the operating voltage and sensitive volume required for attaining certain required sensitivity of measurements.

The filling gas depends on the purpose of measurement. For measuring neutrons, $\mathrm{BF}_{3}$ is required. For other types of radiations, $\mathrm{Ar}, \mathrm{Kr}, \mathrm{Xe}$ and $\mathrm{He}$ are usually used with a pressure in the order of $100-200 \mathrm{~cm} \mathrm{Hg}$. The quinching gas of partial pressure $5-10 \mathrm{cmHg}$.

* Miltary Technical College, Chemical Engineering Dpartment. 
The quinching gas is either organic or inorganic. In organic gas quinching, the GMT has a
finite life time of order $10^{8}$ quenching with halogen, the regeneration process of to dissociation of organic molecules. In plateau slope is higher than in case of organic quinching halogen (mostly bromine). The organic quinching quinching. The inorganic quinching gas is usually $[1,2,3]$.

The nuclear radiation interacts with the filling gas of the GMT producing ion pairs and excited molecules. In presence of high electric field, the electrons are attracted to the positive electrode acquire enough energy that cathode. The electrons are accelerated by the high electric field and ionizations are very great near tha positive to cause secondary ionizations. These secondary positive electrode. The electrons are collected rapidel Therefore, avalanches are formed near the the counter and form a positive sheath arod rapidely, while the positive ions are still slower in screan reduces the electric field to such an the anode acting as an electrostatic screan. This strike the cathode, their deexcitations take pont that discharge should stop. When positive ions ion pairs and consequently false pulsesare excitation energy in decomposition of quinching gas and not to produinching gas is to exhaust the The number of pulses depend on false pulses $[1$ - 5].

The number of pulses depend on the radiation level. These pulses do not have the same shape and this is a natural characteristic of GMT [4,5]. Typical values of dead times of GMT are from 10 these pulses are integrated directly by simple integration circuit which consists of capacitor be shaped before their integration.

\section{EXPERIMENTAL PROCEDURE}

The following GMT was designed and executed :

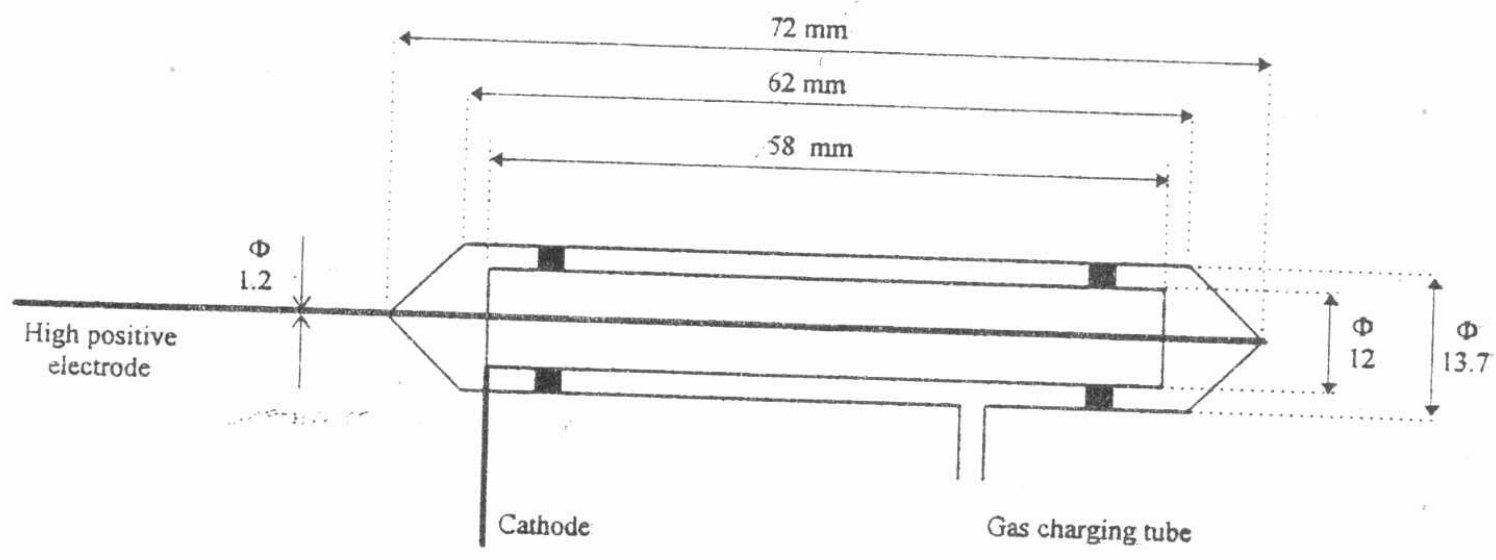

The designed GMT in the laboratory 
The GMT was connected to gas circuit with evacuation. The gas circuit was filled with $\mathrm{He}$ or $\mathrm{Ar}$ gases at different pressures with and without quenching gases. The pressures of gases ranged from $10-1520 \mathrm{~cm} \mathrm{Hg}$ and those of quenching gas ranged from $20-152 \mathrm{~cm} \mathrm{Hg}$. The GMT was connected to an electric circuit to determine its optimum operating voltage at each condition .

The required converter was designed and executed, to transfer the small DC voltage of small battery ( $1.5-3$ volt) to the higher stabilized voltage required for the operation of the GMT (500 1000 volts). Its main idea is to transfer the $\mathrm{DC}$ current to $\mathrm{AC}$ one, and by transformer, the $\mathrm{AC}$ voltage can be raised to the required $\mathrm{AC}$ value by choosing the required ratio of number of windings of secondary coil to that of primary one.

Rectification of the obtained AC high voltage was performed by a rectifier. Filtration process was performed by a capacitor. Stabilization of voltage was made by corona stabilizer. The designed converter circuit is as follows:

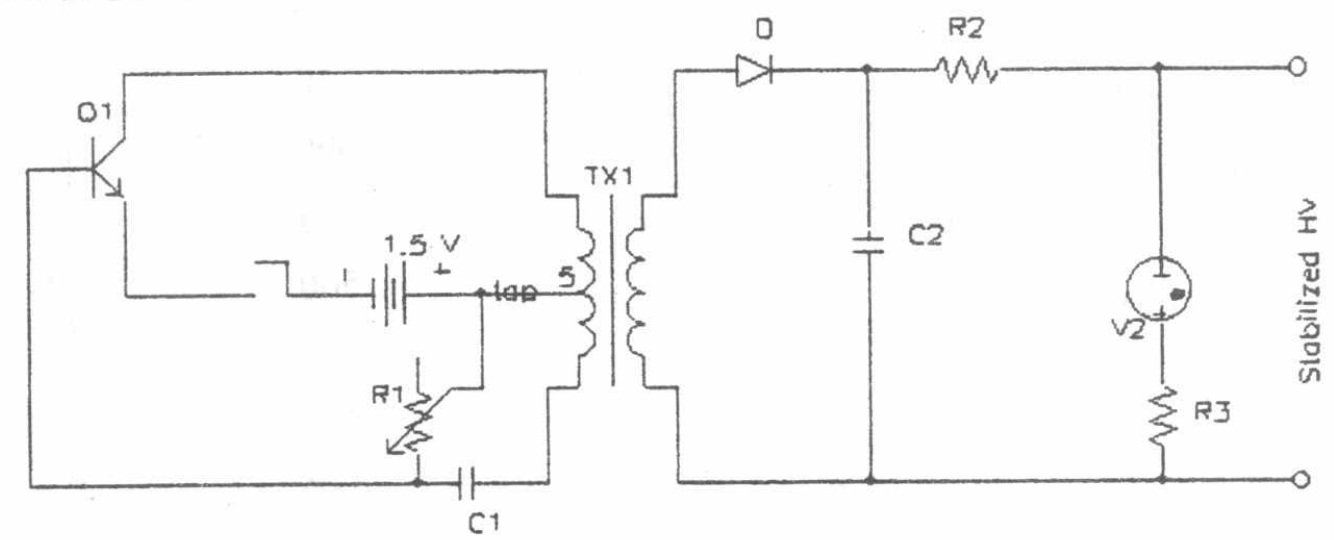

The designed converter suitable for portable radiation meters and GMT

The designs of different radiation meters were performed and different types were made. The block diagram of these instruments can be represented simply as follows:

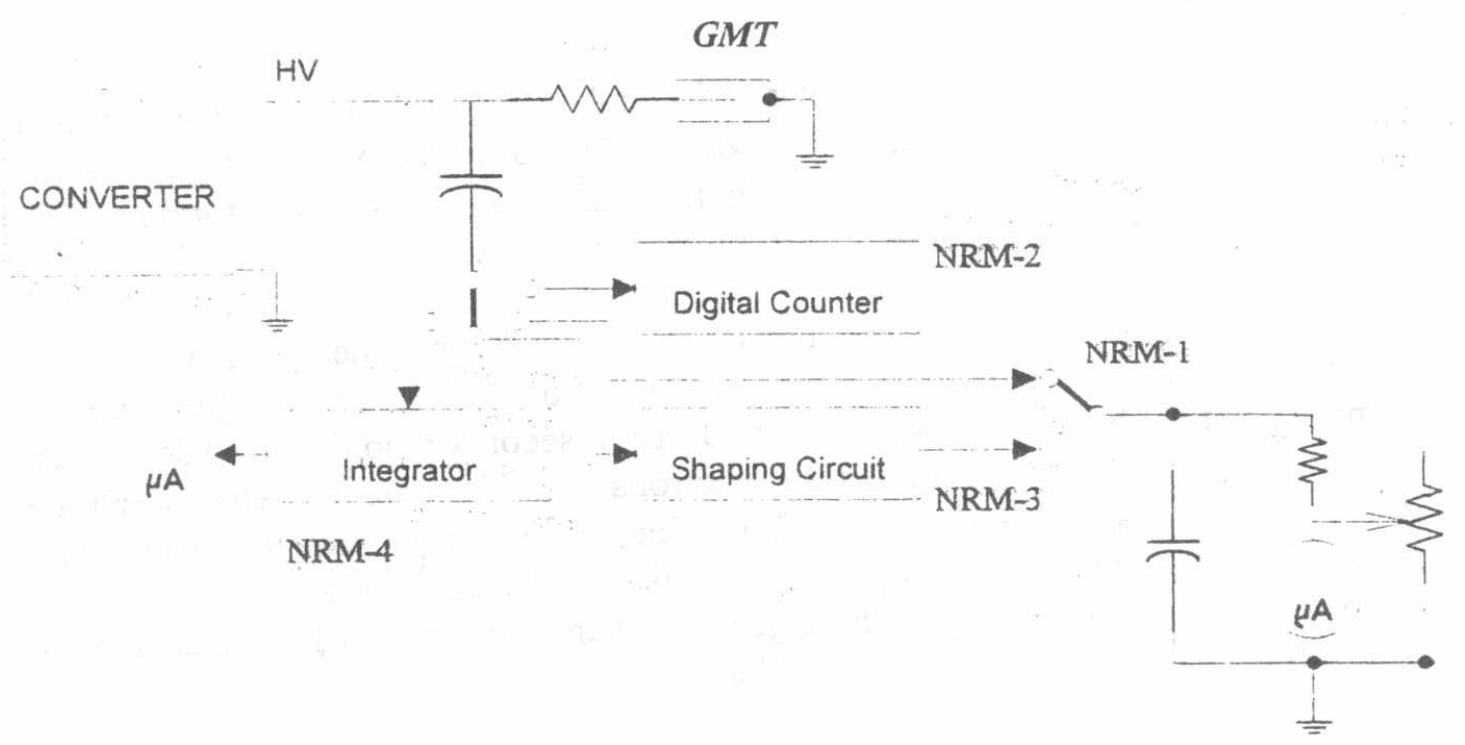

The block diagram of proposed and designed radiation meters 

After the different radiation meters had been prepared, and checked for being sensitive for
radiation,, the NRM-1 \& NRM-2 were calibrated.

\section{RESULTS AND DISCUSSION} The designed GMT was charged with $\mathrm{He}$ and $\mathrm{Ar}$ at different pressures. The corresponding
operating voltages at each condition is shown in the following table:

Table (1) Pressure of charging gas and corresponding operating voltage of GMT

\begin{tabular}{|c|c|c|}
\hline \multirow{2}{*}{$\begin{array}{c}\text { Pressure } \\
\text { (cm Hg) }\end{array}$} & \multicolumn{2}{|c|}{ The corresponding operating voltage (volts) } \\
\cline { 2 - 3 } & in He & in Ar \\
\hline 10 & 425 & 420 \\
265 & 475 & 460 \\
385 & 600 & 490 \\
510 & 655 & 495 \\
635 & 680 & 500 \\
760 & 760 & 510 \\
1140 & 790 & 540 \\
1520 & 948 & 560 \\
\hline
\end{tabular}

The results show that the operating voltages of GMT in case of charging with $\mathrm{He}$ are greater than those of charging the $\mathrm{Ar}$ at the same values of pressures. Also, when the charging pressure of the
$\mathrm{GMT}$ increases, the operating voltage increases

The decrease of ionization potential of Ar than that of He makes the ionization of Ar easier than that of $\mathrm{He}$ and this interprets why lower electric field will be needed in case of Ar for acceleration avalanches), As a result, a lower operating voltage will be susbected [7].

Results showed also that the increase of pressure inside the GMT increased the operating voltage. This is expected since at higher pressure, the collisions of electrons with the filling gas increase. As a result, the mean free path of electrons ( emitted from secondary ionization) decreases. Therefore, Higher voltage is required to attract the electrons to the positive collecting electrode and hence, higher operating voltage is expected [3,6]. The same reason explains why higher operating voltages of GMT in when quenching gas of higher molecular weight is added. The used gas was ethylalcohol vapour of partial pressure $10 \%$. given in the table (2). The quenching 
Table(2) The operating voltages of GMT in presence of quenching gas

\begin{tabular}{|c|c|c|c|}
\hline \multirow{2}{*}{$\begin{array}{l}\text { Pressure of ethyl alcohol } \\
\text { (cm Hg) }\end{array}$} & \multirow{2}{*}{$\begin{array}{l}\text { Pressure of } \mathrm{He} \text { or } \mathrm{Ar} \\
\text { (cm Hg) }\end{array}$} & \multicolumn{2}{|c|}{ Operating voltage (V) } \\
\hline & & in case of $\mathrm{He}$ & in case of $\mathrm{Ar}$ \\
\hline 20 & 180 & 1030 & 920 \\
\hline 51 & 459 & 1160 & 1110 \\
\hline 76 & 684 & 1320 & 1200 \\
\hline 114 & 1026 & 1580 & 1300 \\
\hline 152 & 1368 & 1640 & 1380 \\
\hline
\end{tabular}

Larger volumes of GMT will require higher operating voltage and they are more sensitive since they have higher sensitive volumes $[3,5,6]$. Shortly, higher volumes, higher pressure of filling inert gas, lower radius of atoms of filling gas and existance of heavier quenching gas cause increase in required operating voltage of the designed GMT.

The work done in this study needs further development for the routine production of nuclear radiation meters. The calibration process was made for NRM-1 \& NRM-2 using cobalt-60 source on the dose rate ranges : $1-100 \mathrm{mRad} / \mathrm{h} \& 1-100 \mathrm{Rad} / \mathrm{h}$ by adjusting the meter at the value 40 and measuring at positions of $10,25,60$ for each range. The errors in readings were less than $21 \%$ compared with $30 \%$ for the similar universal imported portable radiation meters. This result is a good base for the development of technological production of nuclear radiation meters.

\section{REFFERENCES}

1- Margaritondo, G., "Introduction To Synchrotron Radiation" Oxford Untiversitypress, New York, P 85 (1988).

2- Dulap, R. A., "Experimental Physics. Modern Methods", Oxford University Press, New Yyork, P. 303 (1988).

3- Prlce, W. J., "Nuclear Radiation Detection" Metor Hill, New York, P..115-145 (1958)

4-Sharpe, J., "Nuclear Radiation Detectors", London, Wiley, P. 102 - 200 (1955).

5- Tsoulfanidis, N., " Measurement And Detection Of Radiation ", Hemi Sphere Publishing Corporation, New York, P. 185 (1983).

6- Attix, F. H. , And Roesch, W. C., "Radiation Dosimetry ", Academic Press, New York. P. 317 (Vol-I) \& P.73 ( Vol.2) (1968).

7- Prakash , S, Tuli, G. D., Basu, S. K., And Madan, R. D., "Advanced Inorganic Chemistry", S. Chand \& Company Ltd., New Delhi, P.72 (1981). 